\title{
Passive Samples (POCIS) in Ponds and Wetlands to Evaluate Pesticide Degradation using Compound- Specific Isotope Analysis
}

\author{
Tetyana Gilevska, Jeremy Masbou, Baptiste Baumlin and Gwenaël Imfeld
}

Laboratory of Hydrology and Geochemistry of Strasbourg (LHyGeS) University of Strasbourg/ENGEES, UMR 7517 CNRS, 1 rue Blessig, 67084 Strasbourg, France

Passive samplers have been used widely as an alternative to the traditional grab water sampling method as they i) allow pre-concentration of micropollutants, ii) integrate average contaminant concentrations over extended sampling periods and ii) minimize the sampling logistic ${ }^{1}$. The use of passive samplers is particularly beneficial when environmental concentrations vary strongly over time. In this case, the grab sampling approach can miss important input from short events such e.g. storm-events and bias interpretation of micropollutant transfer. Compound-specific isotope analysis (CSIA) allows teasing apart the contribution of non-degradative (dilution, sorption) and degradative processes both resulting in overall pollutant dissipation ${ }^{2}$. CSIA is widely applied for industrial contaminated sites, with a relatively high concentration of contaminants. However, is less often extended to micropollutants, as herbicides and pharmaceuticals, due to smaller environmental concentrations. Here we developed the application of commercially available polar organic chemical integrative sampling (POCIS) for simultaneous evaluation of concentration and carbon CSIA of herbicides (atrazine, metalaxyl, terbutryn, S-metolachlor, tebuconazole, dimethomorph) in artificial wetlands receiving pesticide runoff from a vineyard catchment (42.7 ha, Alsace, France).

Prior to field deployment, POCIS performance was tested for sorption and subsequent isotope analysis of selected herbicides for different concentrations, matrices (distilled vs. pond water), flow conditions, and hydrogeological events patterns. In parallel, self-made POCIS samplers were prepared and compared to the commercially available passive samplers. Our results show that i) pesticide sorption on POCIS is linear for concentrations below $10 \mu \mathrm{g} / \mathrm{L}$, ii) extraction from POCIS causes no significant isotopic effect for studied herbicides, iii) commercial and self-made POCIS did not differ in terms of concentration and $\delta^{13} \mathrm{C}$ measured in extracts and iv) POCIS records accurately changes of isotope signatures of pollutants in water. As POCIS techniques are not selective to the molecules of interest, the only limitation arises sporadically from matrix effects for some compounds in complex matrices, a common problem in CSIA from environmental samples. This issue can be solved in the future with a further combination of POCIS with further matrix cleanup techniques.

Finally, POCIS was deployed into the storm-water pond located at the outlet of the vineyard catchment for intervals of 28 days over 3 months. All the compounds detected in the grab water samples (10L) taken in parallel were found in POCIS. In particular, the widely used fungicide dimetomorph was pre-concentrated in POCIS extracts up to $2 \mathrm{mg} / \mathrm{L}$ compared to the surrounding water average concentration of $100 \mathrm{ng} / \mathrm{L}$. This high preconcentration factor (x 20'000) makes CSIA of dimetomorph feasible, supporting assessment of degradation in the field. Altogether, we anticipate this study to be a starting point for the application of multi-element CSIA to assess the fate of a variety of micropollutants in surface waters.

\section{References}

1. Alvarez, D. A.; Petty, J. D.; Huckins, J. N.; Jones-Lepp, T. L.; Getting, D. T.; Goddard, J. P.; Manahan, S. E. Development of a Passive, in Situ, Integrative Sampler for Hydrophilic Organic Contaminants in Aquatic Environments. Environ. Toxicol. Chem. 2004. https://doi.org/10.1897/03-603.

2. Hunkeler, D.; Meckenstock, R. U.; Sherwood Lollar, B.; Schmidt, T. C.; Wilson, J. T. A Guide for Assessing Biodegradation and Source Identification of Organic Ground Water Contaminants Using Compound Specific Isotope Analysis (CSIA). USEPA Publ. 2008, 600/R-08/1 (December), 1-82. 
(C) 2020 by the authors; licensee MDPI, Basel, Switzerland. This article is an open access article distributed under the terms and conditions of the Creative Commons by Attribution (CC-BY) license (http://creativecommons.org/licenses/by/4.0/). 